This item was submitted to Loughborough's Research Repository by the author.

Items in Figshare are protected by copyright, with all rights reserved, unless otherwise indicated.

\title{
Broad-scale patterns of invertebrate richness and community composition in temporary rivers: effects of flow intermittence
}

PLEASE CITE THE PUBLISHED VERSION

http://dx.doi.org/10.1111/j.1600-0587.2013.00287.x

\section{PUBLISHER}

Wiley / @ The Authors. Ecography @ Nordic Society Oikos

\section{VERSION}

AM (Accepted Manuscript)

\section{PUBLISHER STATEMENT}

This work is made available according to the conditions of the Creative Commons Attribution-NonCommercialNoDerivatives 4.0 International (CC BY-NC-ND 4.0) licence. Full details of this licence are available at: https://creativecommons.org/licenses/by-nc-nd/4.0/

\section{LICENCE}

CC BY-NC-ND 4.0

\section{REPOSITORY RECORD}

Datry, T., S.T. Larned, K.M. Fritz, M.T. Bogan, Paul J. Wood, E.I. Meyer, and A.N. Santos. 2019. "Broad-scale Patterns of Invertebrate Richness and Community Composition in Temporary Rivers: Effects of Flow Intermittence". figshare. https://hdl.handle.net/2134/16646. 
1 Broad-scale patterns of invertebrate richness and community composition

2 in temporary rivers: effects of flow intermittence

3 T.Datry $^{1}$, S.T. Larned ${ }^{2}$, K.M. Fritz ${ }^{3}$, M.T. Bogan ${ }^{4}$, P.J. Wood ${ }^{5}$, E.I. Meyer ${ }^{6}$, and A.N. Santos ${ }^{7}$

4

$5 \quad{ }^{1}$ Institut national de Recherche en Sciences et Technologies pour l'Environnement et

6 l’Agriculture, Lyon, France, thibault.datry@irstea.fr

$7 \quad{ }^{2}$ National Institute of Water and Atmospheric Research, Christchurch, New Zealand,

8 scott.larned@niwa.co.nz

$9 \quad{ }^{3}$ US-Environmental Protection Agency, Cincinnati, Ohio, USA, fritz.ken@epa.gov

$10 \quad{ }^{4}$ Oregon State University, Corvallis, Oregon, USA, boganmi@science.oregonstate.edu

$11{ }^{5}$ Loughborough University, Leicestershire, UK, p.j.wood@lboro.ac.uk

$12 \quad{ }^{6}$ University of Münster, Münster, Germany, meyere@uni-muenster.de

$13 \quad{ }^{7}$ Texas A\&M University, College Station, Texas, USA, annasantos@neo.tamu.edu

14

Corresponding author: T. Datry, IRSTEA, UR MALY, 5 rue de la Doua, CS70077, 69926

Villeurbanne Cedex, France. Tel (33) 4.72.20.87.55 Fax (33) 4.78.47.78.75,

thibault.datry@irstea.fr

18

Running title: Invertebrate community patterns in temporary rivers

4 figures and 3 tables

2 Supplementary materials (S1, S2)

Number of references: 49

No. words: i. main text: 4006; ii. abstract: 251; iii. total including S1 and S2: 6943 
Abstract (251 words)

27 Temporary rivers are increasingly common freshwater ecosystems, but there have been no global syntheses of their community patterns. In this study, we examined the responses of aquatic invertebrate communities to flow intermittence in 14 rivers from multiple biogeographic regions and covering a wide range of flow intermittence and spatial arrangements of perennial and temporary reaches. Hydrological data were used to describe flow intermittence (FI, the proportion of the year with zero-flow) gradients. Linear mixedeffects models were used to examine the relationships between FI and community structure and composition. We also tested if communities at the most temporary sites were nested subsets of communities at the least temporary and perennial sites. Taxon richness decreased as FI increased and invertebrate communities became dominated by ubiquitous taxa. The number of resilient taxa (with high dispersal capacities) decreased with increased FI, whereas the number of resistant taxa (with adaptations to desiccation) was not related to FI. Riverspecific and river-averaged model comparisons indicated that most FI-community relationships did not differ statistically among rivers. Community nestedness along FI gradients was detected in most rivers and there was little or no influence of the spatial arrangement of perennial and temporary reaches. These results indicate that FI is a primary driver of aquatic communities in temporary rivers, regardless of the biogeographic species pool. Community responses are largely due to resilience rather than resistance mechanisms. However, contrary to our expectations, resilience was not strongly influenced by spatial fragmentation patterns, suggesting that colonist sources other than adjacent perennial reaches were important.

48 Keywords: climate change, temporary rivers, habitat fragmentation, resistance, resilience, biodiversity, life-history traits 


\section{Introduction}

52 Identifying general relationships between environmental drivers and community responses is a perennial goal in ecology. Common environment-community relationships are represented by linear or curvilinear relationships that are congruent in direction (increasing or decreasing) and magnitude (slope or inflection) for geographically separated and/or phylogenetically distinct communities. For example, the shapes of relationships between water availability and primary productivity (drivers) and the diversity of bat, amphibian, and bird communities (responses) are remarkably similar over wide biogeographic ranges (Mittelbach et al. 2001, McCain 2007). These observations suggest that some environmental factors are "master variables" with strong direct or indirect effects on most communities in a given taxonomic group or habitat type (Menéndez et al. 2007). Other environmental factors are subsidiary; their effects on community structure are weak or localized. General relationships between environmental drivers and community structure can provide mechanistic explanations for widely observed spatial patterns, including latitudinal and altitudinal gradients in community diversity (McCain 2007), regional beta-diversity patterns (Melo et al. 2009), species-area relationships (Öckinger et al. 2010) and intercontinental community convergence (Lamouroux et al. 2002).

Although temporary rivers drain all terrestrial biomes and represent the dominant freshwater ecosystems in many areas, they have only recently been considered by ecologists (Larned et al. 2010, Datry et al. 2011, Steward et al. 2012). As a result, the organisation of aquatic communities in these systems has never been analysed across different biogeographic regions.

73 The periodic loss of surface water (hereafter "flow intermittence") is a fundamental challenge 74 for aquatic organisms and may be a major driver of aquatic community diversity and composition. Alteration of aquatic communities caused by flow intermittence may also have 
cascading effects on biotic communities in adjacent ecosystems, such as riparian and floodplain areas (McCluney and Sabo 2012) or hyporheic zones (Datry et al. 2007). There are some indications that aquatic invertebrate communities in geographically distant river systems display similar responses to variation in flow intermittence. For example, invertebrate taxon richness in temporary rivers of France, New Zealand and the USA decreased linearly as the severity of flow intermittence increased (Fritz and Dodds 2004, Arscott et al. 2010, Datry 2012). Partial and complete overlap in taxonomic composition has also been reported for invertebrate communities from adjacent temporary and perennial reaches (e.g., del Rosario and Resh 2000, Chester and Robson 2011). These observations suggest that intermittencespecialist taxa are rare. However, the previous studies of aquatic invertebrates in temporary rivers have been site- or river-specific and differed in aims and methods, preventing the identification of general community patterns and mechanisms.

Aquatic communities of temporary rivers persist through disturbances using both resistance and resilience mechanisms (Fritz and Dodds 2004, Bêche et al. 2009). Resistance reflects the capacity of communities to persist unchanged through periods without surface water and involves a range of physiological adaptations allowing organisms to survive within dry riverbed sediments or remnant pools (Lytle and Poff 2004, Williams 2006). For example, species from several invertebrate groups (e.g., oligochetes, copepods, dipterans) can persist for years in dry river sediments as cysts and cocoons, or in a state of diapause as larvae or adults (Williams, 2006). In this way, resistance can be viewed as a form of temporal dispersal (Bohonak and Jenkins 2003). Resilience reflects the ability of communities to return to their pre-drying state soon after flow resumes. Resilience to flow intermittence may be related to aerial or instream dispersal capacity, which governs the rate at which taxa return to a rewetted river channel from aquatic refuges (Stanley et al. 1994, Chester and Robson 2011). 
102 While the respective roles of resistance and resilience mechanisms in structuring diversity patterns in temporary rivers are currently unclear, a global analysis of diversity patterns across temporary rivers might help disentangle the roles of these mechanisms. If resistance is the

105 principal persistence mechanism for invertebrates in temporary rivers, relationships between

106 flow intermittence and invertebrate taxon richness should be weak or nonexistent (Fig. 1A).

107 Additionally, the composition of temporary-reach communities should differ from those in 108 perennial reaches because of a progressive replacement of taxa along flow intermittence 109 gradients, particularly if there is a cost associated with desiccation-resistance adaptations

110 (Fig. 1B). In contrast, if resilience is the principal persistence mechanism, the progressive 111 colonization of previously-dry reaches by taxa from nearby aquatic refuges should result in 112 negative relationships between flow intermittence and taxon richness, and these relationships 113 should be congruent across rivers (Fig. 1A). In addition, taxa -poor communities at the most 114 temporary reaches should be nested-subsets of taxa -rich communities found at the least 115 temporary and/or perennial reaches (Fig. 1B).

117 Flow intermittence in river networks can lead to different spatial arrangements of perennial 118 and temporary reaches and thus different patterns of habitat fragmentation (Lake 2003). In 119 many river networks, temporary reaches are concentrated in the upper, middle or lower 120 reaches of rivers (Fig. 1C). These large-scale drying patterns can influence the effects of 121 fragmentation on dispersal and create mismatches in the geometries of dispersal and 122 disturbance (drying phase) (Fagan 2002). Downstream transport of materials (via stream 123 flow) is a dominant feature in lotic ecosystems and not all aqutic invertebrate taxa frequently 124 disperse overland (Bohonak and Jenkins 2003). Therefore, the accessibility of refuges for 125 aquatic invertebrates during dry periods, and dispersal pathways from these refuges following 
rewetting may differ due to the variable spatial arrangements of temporary and perennial reaches (Fig. 1C). The overall responses of aquatic organisms to flow intermittence should thus vary with the pattern of habitat fragmentation, particularly if (instream?) dispersal is an overriding mechanism for explaining community persistence in temporary rivers.

131 In this study, we investigated the responses of aquatic invertebrate communities to flow

132 intermittence in multiple biogeographic regions. We hypothesized that the persistence of communities in temporary rivers is primarily associated with resilience mechanisms, not resistance mechanisms. Based on the attributes of resilience-structured invertebrate

135 communities described above and in Figure 1, we predicted that invertebrate communities in 136 temporary rivers would be characterized by negative taxon richness-flow intermittence 137 relationships, and by community nestedness along flow intermittence gradients. Given 138 dispersal limitations of many invertebrate taxa, we expected these patterns to vary with the 139 spatial arrangement of temporary reaches within river systems. To test our predictions, we 140 used data from 128 sites in 14 temporary rivers across Europe, North America, and New 141 Zealand. The datasets encompassed a wide range of flow intermittence and spatial 142 arrangements of perennial and temporary reaches.

\section{Method}

\section{Data sets}

146 We compiled datasets from aquatic invertebrate studies of 14 temporary rivers in Europe 147 (seven rivers), North America (five rivers), and New Zealand (two rivers). The datasets 148 consisted of matrices of invertebrate taxa, abundances and sampling dates at multiple sites 149 within temporary and perennial river reaches. The average number of days between two 150 consecutive sampling events on a given site was $146.5 \pm 74.5 \mathrm{~d}$ (SD?), and the average 
151 distance between sites was $3.1 \pm 2.6 \mathrm{~km}$. At each site, invertebrates were collected from riffle

152 habitats using standardized and comparable sampling methods (Surber, Hess, and kick-net 153 samplers with mesh sizes ranging from 250 to $500 \mu \mathrm{m}$ ) from at least three sites per river

154 (Table 1). The datasets were classified by the spatial arrangement of perennial and temporary 155 reaches (upper, middle and lower reach drying, Table 1). For further information on the 156 individual studies, see the references in Table 1, and details about methods and sites in 157 Appendix S1.

158

159 Quantification of flow intermittence

160 For each data set, annual flow intermittence (FI), the proportion of the year with zero-flow,

161 was calculated for each sampling site. One of three procedures outlined below was used to

162 calculate FI values for the sampling sites in each river, reflecting the type of flow 163 measurement and quantity of discharge data available in each study. River discharge was 164 standardized to $\mathrm{L} \mathrm{s}^{-1}$.

166 Hydrological modelling. For five datasets (Albarine, Asse, Little Stour, Orari, Selwyn), mean 167 daily flow (including zero-flow) at sampling sites were estimated using the statistical model 168 ELFMOD (Larned et al. 2011). For each river, the input data consisted of manual 169 measurements of discharge at sampling sites on $\geq$ nine dates, and continuous discharge from 170 at least two permanent recorders that bounded the study reaches. The discharge time-series 171 from each recorder was $\geq 10$ years long, and included the study period during which 172 invertebrate samples were collected. Modelled mean daily discharge was used to calculate FI 173 for each site each year. 
175 Direct measurement. For four datasets (Garden, Huachuca, Little Lusk, Sycamore), water-

176 state loggers were used to record the presence or absence of water during the invertebrate 177 sampling period (Fritz et al. 2006, Jaeger and Olden 2012). FI was calculated for each

178 sampling site from the logged time-series. Estimates of FI based on ELMOD and water-state

179 loggers at sampling sites along the Albarine River were highly correlated $(r=0.93, P<$ $180 \quad 0.001, n=9)$.

181

182 Direct observations. For five datasets (Alme, Ellerbach, Fish Brook, Menne, Sauer) FI was 183 estimated at sampling sites using weekly to bi-monthly observations of flow state (flowing or 184 completely dry) for three to 12 months. Point gauging data and discharge data from adjacent 185 gauging stations were then used to assess flow-state patterns between consecutive 186 observations (Meyer et al. 2003).

\section{Invertebrate variables}

189 For each sample in the invertebrate datasets, taxon richness (TR) was calculated as the 190 number of taxa per sample. To account for differences in taxonomic resolution among 191 datasets, TR was calculated at three levels of resolution: fine (TR1), medium (TR2), and coarse (TR3). The degree of taxonomic consistency among datasets increases and taxonomic precision decreases from TR1 to TR3. The taxonomic groups used at each level of resolution

194 are shown in Table 2.

196 To describe the communities in each dataset in terms of taxonomic composition and life197 history traits, the relative abundances of Coleoptera, Diptera, Oligochaeta, and the sum of 198 Ephemeroptera, Plecoptera and Trichoptera (hereafter 'EPT') were calculated in each sample. 199 In addition, each taxon in each dataset was classified into one of four classes using life-history 
and biological traits: resistant, resilient, both resistant and resilient, or neither resistant nor

201 resilient. Trait classification was undertaken at the coarsest taxonomic level (TR3) to maximize consistency across datasets although this reduced our ability to detect fine-scale patterns. We assigned the following traits to the resilient class: long adult lifespan, high female dispersal, strong adult flying ability, common occurrence in drift, and strong 205 swimming ability. We assigned the following traits to the resistant class: presence of 206 desiccation-resistance forms (e.g., cysts, cocoons, diapause stages), body armouring limiting 207 water loss (including the use of external cases), plastron/spiracle respiration, and low rheophily. We used published (Tachet et al., 2002, Poff et al. 2006, Bonada and Doledec 2011) and unpublished (V. Archaimbault, personal communication) trait information to 210 classify each taxon (Appendix S2). Given the coarse taxonomic resolution used (TR 3), we 211 assigned to each taxon the traits which were dominant across the constituent families, genera or species. When the traits assigned to a taxon were from the resistant class exclusively, it was classified as resistant $(n=37$ taxa). Conversely, when the traits assigned to a taxon were

214 from the resilient class exclusively, it was classified as resilient ( $\mathrm{n}=37$ taxa). When the traits 215 assigned to a taxon were from both the resistant and resilient classes, it was classified as 216 resistant and resilient $(\mathrm{n}=26$ taxa). Last, when no traits from the resistant or resilient classes were assigned to a taxon, it was classified as neither resistant nor resilient ( $\mathrm{n}=25$ taxa). For

21812 out of 125 taxa, there was no information available regarding resistence and resilience 219 traits, and classification was based on closely related taxa for which there was some 220 information and authors' knowledge.

\section{Statistical analyses}

223 The invertebrate community variables described above were used as dependant variables in 224 linear mixed-effects models with Gaussian error distributions. Analyses were undertaken 
using the lme4 package for R (R Development Core Team 2008). For each dependent

226 variable, we tested for effects of FI and then tested if these effects differed between rivers and spatial drying patterns. We compared three nested mixed-effects models that progressively

228 increased in complexity. The first model (null) was a null model with a random intercept. The 229 second model (average) was an average model with a fixed effect of FI across all rivers. The 230 third model (river-specific) was a model with a random effect of FI, which was allowed to 231 vary among rivers (Bolker et al. 2009). River was entered as a random effect in each model. 232 When slopes differed among rivers, we fitted additional models adding longitudinal drying 233 pattern as a fixed effect to test for possible systematic effects of the spatial arrangement of 234 perennial and temporary reaches. The statistical significance levels for the fixed and random 235 effects in the best-fitting models were determined using likelihood-ratio tests on models with 236 and without each effect (Bolker et al. 2009). To select the most parsimonious models, we used 237 the minimum Akaike's Information Criterion (AIC). We checked for normality and 238 homogeneity by visual inspections of plots of residuals against fitted values. When average 239 models were selected, we used individual linear regressions to analyse how much individual 240 rivers contributed to the average model.

242 Nestedness analyses were used to determine whether invertebrate communities at the most 243 temporary sites were nested subsets of communities found at the least temporary and 244 perennial sites. Such patterns would indicate a selective loss of taxa susceptible to drying 245 rather than a replacement of perennial-flow specialists with intermittent-flow specialists along 246 flow intermittence gradients. We tested for community nestedness of both taxa incidence and 247 composition along the flow intermittence gradient at each river and at each taxonomic level 248 (TR1, 2 and 3) using the Brualdi and Sanderson discrepancy index, which provides a 249 conservative test for nestedness (Ulrich and Gotelli 2007). The significance of nestedness was 
250

251

252

253

254

255

256

257

258

259

260

261

262

263

264

265

266

267

268

269

270

271

272

273

274

then tested against constrained null models (showing the same marginal totals as the original data) using the “quasiswap” method (Miklós and Podani 2004).

\section{Results}

Taxon richness and flow intermittence

Taxon richness decreased for all taxonomic resolutions with increasing FI (Likelihood ratio tests between null and average models, $\chi^{2}=232.59,248.33$, and 179.78 for TR1, TR2 and TR3, respectively; $P<0.001$; Fig. 2). The slopes of the taxon richness-FI relationships did not differ statistically among rivers as indicated by the comparisons between average and river-specific models $\left(\chi^{2}=1.08,1.07\right.$, and 1.76; $P=0.582,0.586$ and 0.414 , for TR1, TR2 and TR3, respectively, Fig. 2). On average, a 10\% increase in FI resulted in the loss of two taxa at the fine taxonomic level (TR1: slope $=-0.20,95 \%$ CI: $-[0.22: 0.18]$ ), one and a half taxa at the medium taxonomic level (TR2: slope $=-0.16,95 \%$ CI: $-[0.18: 0.15]$ ), and one taxon at the coarse taxonomic level (TR3: slope $=-0.12$, 95\% CI: $-[0.13: 0.10]$ ) (Fig. 2).

\section{Resistance and resilience traits, community composition and flow intermittence}

The significant negative relationships between FI and taxon richness were maintained when resilient taxa and those without resistant nor resilient traits were considered separately (Likelihood ratio tests between null and average models, $\chi^{2}=125.93$ and 136.03, respectively; $P<0.001$ ), but were not significant for resistant taxa or those with both resistant and resilient traits $\left(\chi^{2}=13.61\right.$ and $4.77, P=0.1611$ and 0.8622 , respectively). For resilient taxa and those without resistant nor resilient traits, the slopes of the taxon richnessFI relationships differed statistically among rivers as indicated by the comparisons between average and river-specific models $\left(\chi^{2}=15.09\right.$, and 41.61, respectively ; $\left.P<0.001\right)$. However, these relationships did not differ with respect to the spatial arrangement of perennial and 
275 temporary reaches (Likelihood ratio test, $\chi^{2}=1.87$ and $3.11 ; P=0.7596$ and 0.5384 , 276 respectively).

277

278 The relative abundances of EPT and Coleoptera decreased, and the relative abundance of 279 Diptera increased among rivers as FI increased (Likelihood ratio tests between null and 280 average models, $\chi^{2}=72.89,19.26$, and 73.44, respectively; $P<0.001$, Fig. 3 and 4). The 281 slopes of these relationships did not differ statistically among rivers (Likelihood ratio tests 282 between average and river-specific models, $\chi^{2}=0.27,5.19$, and 6.46; $P=0.871,0.078$, and 283 0.065, respectively, Fig. 3 and 4). On average, for every 10\% increase of FI, there was a 4\% 284 reduction in the relative abundance of EPT taxa (slope $=-0.37,95 \%$ CI: $-[0.45: 0.28]$ ), a $0.5 \%$ reduction in the relative abundance of Coleoptera (slope $=-0.06,95 \%$ CI: $-[0.09: 0.04]$ ) and a $4 \%$ increase in the relative abundance of Diptera (slope $=0.38,95 \%$ CI: [0.30 : 0.47]). There were no detectable relationships between the relative abundance of Oligochaeta and FI (Likelihood ratio tests between null and average models, $\chi^{2}=4.79 ; P=0.092$ ).

\section{Community nestedness along flow intermittence gradients}

291 At the fine taxonomic level, invertebrate communities at the most temporary sites were nested 292 subsets of communities at the least temporary and perennial sites in 10 of the 14 rivers (Table 3). At medium and coarse levels of taxonomic resolution, nestedness tended to occur primarily in rivers with downstream drying patterns (Table 3).

\section{Discussion}

297 We demonstrated general and significant effects of FI on invertebrate taxon richness across 14 298 rivers in Europe, North America and New Zealand. As FI increased, invertebrate communities 299 in these rivers became increasingly taxa-poor. More importantly, the rate of decline in the 
number of taxa along gradients of FI was not statistically different among the 14 rivers tested

301 for each of the three different levels of taxonomic resolution, despite these rivers representing a wide range of climatic and biogeographic conditions and differing markedly in size and spatial drying patterns. Therefore, our results demonstrate a wide-spread congruence in the responses of invertebrates to FI and suggest that FI is a "master variable" driving river community structure and composition. Given the increasing intensity and spatial extent of FI in rivers due to anthropogenic water abstraction and climate change (Meybeck 2003, Larned et al. 2010), our findings indicate the potential for widespread declines in river biodiversity resulting from increased flow intermittence.

Our analysis of diversity patterns helps to disentangle the respective roles of resistance and resilience mechanisms in structuring invertebrate communities in temporary rivers. There are three ways in which our results suggest that, as we hypothesized, invertebrate community patterns along FI gradients are primarily a function of resilience rather than resistance. First, the relationships between taxon richness and FI held across rivers for resilient taxa and for taxa without resistant nor resilient traits, when coded at the family level. In contrast, no

316 relationships were detected between FI and resistant taxa or taxa with both resistant and resilient traits. Second, the relative abundances of groups such as EPT and Coleoptera 318 decreased with FI; many species in these groups are susceptible to desiccation (Williams 2006, Datry et al. 2012) and have resilient traits that facilitate recolonization, such as long

320 life-span or strong flying abilities (Petersen et al. 1999, Bohonak and Jenkins 2003). In 321 contrast, the relative abundance of dipteran taxa increased with FI, and desiccation-resistant traits such as diapause and anhydrobiosis are prevalent among many dipteran families (Frouz et al. 2003). Desiccation-resistant traits are not likely to be uniform across the Diptera as a 324 group, however, and do not constrain their persistence in perennial habitats. Many dipterans 
thrive in perennial sites, and their relative abundances were on average $>25 \%$ in our 14 study

326 rivers. Third, a significant level of community nestedness occurred along most of the FI gradients in this study, which indicates that taxa-poor communities in the most temporary

328 sites were nested-subsets of taxa-rich communities in the least temporary and perennial sites.

329 Community nestedness was probably the result of both limited dispersal from source 330 communities in perennial reaches and local extinction along FI gradients (McAbendroth et al. 331 2005). This suggests that the distribution of aquatic refuges across river landscapes, combined 332 with taxa-specific differences in dispersal abilities may explain much of the colonization and 333 succession dynamics in temporary rivers.

335 Although dispersal appears to be an overriding mechanism for explaining community 336 persistence in temporary rivers, there was very little evidence that the pattern of habitat 337 fragmentation (i.e., different spatial arrangements of perennial and temporary reaches) had a 338 strong influence on the responses of invertebrate communities to FI. The FI-taxonomic 339 richness relationships did not vary among spatial arrangements of perennial and temporary 340 reaches. Community nestedness at the coarsest taxonomic level was restricted to rivers with 341 downstream drying patterns. While this partly supports our initial prediction, it also indicates 342 that confounding factors may obscure the effect of spatial fragmentation patterns on aquatic 343 invertebrate communities. It is likely that the magnitude and dynamics of drying and 344 rewetting alter the effects of spatial drying patterns on the responses of invertebrate 345 communities to FI. Complete riverbed drying can occur within a few hours, or disconnected 346 pools can persist for several weeks in otherwise dry riverbeds. Rewetting may be gradual 347 (e.g., expanding pools driven by groundwater upwelling) or rapid (e.g., flash-flood bores 348 driven by runoff). These variable transitions between wet and dry periods are likely to 349 influence the ability of invertebrates to disperse to and from refuges (Bogan et al. 2013). Last, 
refuges adjacent to (parafluvial ponds, lakes, springs) and beneath (hyporheic zone) river

351 channels were not included in this study, and could play significant roles in maintaining communities in temporary rivers (Boulton et al. 1998, Williams 2006).

Invertebrate communities in reaches with the highest FI were consistently dominated by generalist and ubiquitous taxa, rather than by temporary-habitat specialists. Even in the three rivers where chironomids (Huachuca and Garden) or coleopterans (Little Stour) were identified to the species level, there was still little evidence of temporary-specialist taxa.

Because rivers with natural flow regimes are characterized by large variations in discharge, including drought periods (Lake 2003, Lytle and Poff 2004), drying may not be an evolutionary force restricted to temporary rivers as previously thought (c.f., Williams 2006, Steward et al. 2012). The absence of apparent temporary-specialist taxa in these rivers contrasts with community patterns in temporary lentic habitats, such as ponds or wetlands, where taxa replacements along decreasing hydroperiod gradients from perennial to temporary-specialists are common (e.g., Wellborn et al. 1996). Such patterns are thought to be

365 driven by trade-offs between traits that facilitate survival in temporary environments (e.g., 366 dormancy stages, desiccation-resistant eggs) and traits that reduce vulnerability to predators 367 (e.g., low activity rates, antipredator morphology) (Skelly 1995, Wellborn et al. 1996). Top aquatic predators (invertebrates, fish) often occur in temporary river reaches (Labbe and

369 Faush 2000), and perhaps such trade-offs do not occur along FI gradients in rivers. However, 370 biotic interactions, including competition and predation, have not been as thoroughly 371 examined in temporary rivers compared to temporary lentic habitats (e.g., Skelly 1995, 372 Wellborn et al. 1996, Spencer et al. 1999), and empirical data to support this hypothesis are currently lacking. If FI increases in extent and severity in the future, we anticipate an

374 increased biotic homogenization of riverine communities, which will in turn modify the 
375 functioning and resilience of river ecosystems (McKinney and Lockwood 1999, Spencer et al. 376 1999).

We demonstrated that invertebrate communities have congruent responses to FI gradients across a range of river sizes in multiple biogeographic regions, and that the spatial arrangement of perennial and temporary reaches had very little influence on these responses.

381 This suggests that FI is a primary driver of aquatic communities in temporary rivers around the world. Resilience explained invertebrate diversity patterns along FI gradients to a greater degree than resistance. However, invertebrate colonization following the resumption of flow remains a poorly-known process and many questions remain (Chester and Robson 2011). For instance, we do not know to what degree successional patterns are predictable, and what abiotic (e.g., distances to refuges, distribution of refuges across landscapes) or biotic drivers (e.g., predation, competition) control succession. Metacommunity and metapopulation dynamics deserve more attention in temporary rivers and more manipulative experiments are needed to improve our understanding of their effects on diversity patterns. In the context of a worldwide biodiversity crisis, whose severity in freshwater ecosystems has been carefully documented (Dudgeon et al. 2006), the general relationships generated in this study may help water managers mitigate the effects of dams, flow diversion, and water abstraction, and will help scientists predict future changes in river biodiversity.

\section{Acknowledgements.}

396 TD thanks R. Corti, G. Le Goff, R. Mons, M. Philippe and P. Roger for help in sample 397 collection, J. Rigaut for invertebrate processing and J. Mouthon for mollusk determination. 398 Funding was provided by the Water Agency RM\&C, Temporary River Ecology Programme.

399 STL thanks D. Arscott, L. Drummond, P. McCaskill and A. Savery for help with sample 
collection and flow gauging, and P. Lambert for invertebrate processing and identification.

401 Funding was provided by the New Zealand Ministry for Science and Innovation,

402

403

404

405

406

407

408

409

410

411

412

413

414

415

416

417

418

419

420

421

422

423

424

425

426

427

428

429

430

Environmental Flows Programme (C01X0308). KMF thanks B. Johnson, L. Winters, E.

Hammer for help in sample collection and B. Thoeny, C. Watson, and P. Weaver for invertebrate processing and identification. The views expressed in this article are those of the authors and do not necessarily represent the views of policies of the U.S. Environmental Protection Agency. MTB thanks D.A. Lytle and K.S. Boersma for help in sample collection and K.L. Jaeger for providing flow intermittence data. Funding was provided by a United States Department of Defense grant (RC-1724) to J.D. Olden and D.A. Lytle. PJW thanks M.D. Agnew and N. Wood for help with sample collection. Funding was provided during the 1996-1997 drought by the Environment Agency of England and Wales. EIM thanks S. Baltzer, M. Drees, K. Gravelaar, S. Knoche, J. Meinhardt, S. Riederer and M. SehmischBartel for sample collection and A. Meyer, C. Göcke, N. Kaschek, H.W. Riss and C. Tödtmannul for help in invertebrate processing and identification. We thank J. Diettrich for hydrological analyses, D.B. Arscott and N. Lamouroux for stimulating discussions, and N. Lamouroux, V. Resh and B. Robson for comments and meticulous editing, which improved the final version of this paper.

\section{Literature Cited}

Arscott, D.B. et al. 2010. Aquatic invertebrate community structure along an intermittence gradient: Selwyn River, New Zealand. - Journal of the North American Benthological Society 29: 530-545.

Bêche, L. A., et al. 2009. Resilience of fishes and invertebrates to prolonged drought in two California streams. - Ecography 32: 778-788.

Bogan, M.T., et al. 2013. Flow intermittency alters longitudinal patterns of invertebrate diversity and assemblage composition in an arid-land stream network. -Freshwater Biology. DOI: 10.1111/fwb.12105.

Bohonak, A.J. and Jenkins, D.G. 2003. Ecological and evolutionary significance of dispersal by freshwater invertebrates. — Ecology Letters 6: 783-796.

Bolker, B.M., et al. 2009. Generalized linear mixed models: a practical guide for ecology and evolution. — Trends in Ecology and Evolution 24: 127-135. 
Bonada, N. and Doledec, S. 2011. Do mediterranean genera not included in Tachet et al. 2002 have mediterranean trait characteristics? — Limnetica 30: 129-142.

Boulton, A.J. et al. 1998. The functional significance of the hyporheic zone in streams and rivers. - Annual Review of Ecology and Systematics 29: 59-81.

Chester, E.T. and Robson, B.J. 2011. Drought refuges, spatial scale and recolonisation by invertebrates in non-perennial streams. - Freshwater Biology 56: 2094-2104.

Datry, T. 2012. Benthic and hyporheic invertebrate assemblages along a flow intermittence gradient: effects of drying events. — Freshwater Biology 57: 563-574.

Datry, T. et al. 2007. Responses of hyporheic invertebrate assemblages to large-sclae variation in flow permanence and surface-subsurface exchange. - Freshwater Biology 52: 1452-1462.

Datry, T. et al. 2011. Recent perspectives on temporary river ecology. - Aquatic Sciences 73: 453-457.

Datry, T. et al. 2012. Spatial and temporal aquatic-terrestrial transitions in the temporary Albarine River, France: responses of invertebrates to experimental rewetting. Freshwater Biology 57: 716-727.

del Rosario, R.B. and Resh, V.H. 2000. Invertebrates in intermittent and perennial streams: is the hyporheic zone a refuge from drying? - Journal of the North American Benthological Society 19: 680-696.

Dudgeon, D. et al. 2006. Freshwater biodiversity: importance, threats, status and conservation. - Biological Reviews 81: 163-182.

Fagan, W.F. 2002. Connectivity, fragmentation and extinction risk in dendritic metapopulations. - Ecology 83: 3243-3249.

Fritz, K.M. and Dodds, W.K. 2004. Resistance and resilience of macroinvertebrate assemblages to drying and flooding in a tallgrass prairie stream. - Hydrobiologia 527: 99112.

Fritz, K.M. et al. 2006. Field Operations Manual for Assessing the Hydrologic Permanence and Ecological Condition of Headwater Streams. EPA 600/R-06/126. USEPA Office of Research and Development, National Exposure Research Laboratory, Cincinnati, $\mathrm{OH}$, USA. http://www.epa.gov/nerleerd/methods/headwater.html

Frouz, J. et al. 2003. Survival strategies of chironomids (Diptera: Chironomidae) living in temporary habitats: a review. — European Journal of Entomology 100: 459-465.

Jaeger, K.L. and Olden, J.D. 2012. Electrical resistance sensor arrays as a means to quantify longitudinal connectivity of rivers. — River Research and Application, 28: 1843-1852.

Labbe, T.R and Fausch K.D. 2000. Dynamics of intermittent stream habitat regulate persistence of a threatened fish at multiple scales. Ecological Applications 10: 1774-1791.

Lake, P.S. 2003. Ecological effects of perturbation by drought in flowing waters. Freshwater Biology 48: 1161-1172.

Lamouroux, N. et al. 2002. Intercontinental convergence of stream fish community traits along geomorphic and hydraulic gradients. Ecology 83: 1792-1807.

Larned, S.T. et al. 2010. Emerging concepts in temporary-river ecology. — Freshwater Biology 55: 717-738.

Larned, S.T. et al. 2011. Longitudinal river ecohydrology: flow variation down the lengths of alluvial rivers. - Ecohydrology 4: 532-548.

Lytle, D.A. and Poff, N.L. 2004. Adaptation to natural flow regimes. — Trends in Ecology and Evolution 19: 94-100.

McAbendroth, L. et al. 2005. Unravelling nestedness and spatial pattern in pond assemblages. — Journal of Animal Ecology 74: 41-49. 
McCain, C.M. 2007. Could temperature and water availability drive elevational species richness patterns? A global case study for bats. — Global Ecology and Biogeography 16: $1-13$.

McCluney, K.E. and Sabo, J.L. 2012. River drying lowers the diversity and alters the composition of an assemblage of desert riparian arthropods. - Freshwater Biology 57: 91103.

McKinney, M.L. and Lockwood, J.L. 1999. Biotic homogenization: a few winners replace many losers in the next mass extinction. - Trends in Ecology and Evolution 14: 450-453.

Menéndez, R. et al. 2007. Direct and indirect effects of climate and habitat factors on butterfly diversity. - Ecology 88: 605-611.

Melo, A.S. et al. 2009. Environmental drivers of beta-diversity patterns in New-World birds and mammals. - Ecography 32: 226-236.

Meybeck, M. 2003. Global analysis of river systems: from Earth system controls to Anthropocene syndromes. - Philosophical Transactions of the Royal Society B: Biological Sciences 358: 1935-1955.

Meyer, A. et al. 2003. Lotic communities of two small temporary karstic systems (East Westphalia, Germany) along a longitudinal of hydrological intermittency. — Limnologica 33: 271-279.

Miklós, I. and Podani, J. 2004. Randomization of presence-absence matrices: Comments and new algorithms. - Ecology 85: 86-92.

Mittelbach, G.G. et al. 2001. What is the observed relationship between species richness and productivity? - Ecology 82: 2381-2396.

Öckinger, E. et al. 2010. Life-history traits predict species responses to habitat area and isolation: a cross-continental synthesis. — Ecology Letters 13: 969-979.

Petersen, I. et al. 1999. Emergence and lateral dispersal of adult Plecoptera and Trichoptera from Broadstone Stream, U.K. — Freshwater Biology 42: 401-416.

Poff, N.L. et al. 2006. Functional trait richness of North American lotic insects: traits-based ecological applications in light of phylogentic relationships. - Journal of the North American Benthological Society 25: 730-755.

R Development Core Team, 2008. R: a language and environment for statistical computing. $\mathrm{R}$ foundation for statistical computing. Vienna. http://www.R-project.org.

Santos, A.N., and Stevenson R.D. 2011. Comparison of macroinvertebrate diversity and community structure among perennial and non-perennial headwater streams. Northeastern Naturalist 18: 7-26.

Skelly, D.K.1995. A behaviour trade-off and its consequences for the distribution of pseudacris treefrog larvae. - Ecology 76: 150-164.

Spencer, M. et al. 1999. Species richness and the proportion of predatory animal species in temporary freshwater pools: relationships with habitat size and permanence. - Ecology Letters 2: 157-166.

Stanley, E.H. et al. 1994. Invertebrate resistance and resilience to intermittency in a desert stream. - American Midland Naturalist 131: 288-300.

Steward, A.L. et al. 2012. When the river runs dry: human and ecological values of dry riverbeds. - Frontiers in Ecology and the Environment 10: 202-209.

Tachet, H. et al. 2002. Invertébrés d'eau douce (2nd corrected impression). CNRS Editions, Paris, France. 588 p.

Ulrich, W. and Gotelli, N.J. 2007. Null model analysis of species nestedness patterns. Ecology 88: 1824-1831.

Wellborn, G.A. et al. 1996. Mechanisms creating community structure along a freshwater habitat gradient. - Annual Review of Ecology and Systematics 27: 337-363. 
528 Williams, D.D. 2006. The Biology of Temporary Waters. Oxford University Press, Oxford, $529 \quad$ U.K., 337 p.

530 Wood, P.J. and Armitage, P.D. 2004. The response of the macroinvertebrate community to low flow variability and supra-seasonal drought within a groundwater dominated river. Archiv für Hydrobiologie 161: 1-20.

\section{Supplementary Material}

Additional Supporting Information may be found in the online version of this article:

Appendix S1 \{Characteristics of individual studies

Appendix S2 \{List of life-history traits coded to assign each taxon to the following class: 0; 
540 Table 1. Description of the 14 temporary rivers. More details are available on Appendix 1. Unpub.: unpublished data.

\begin{tabular}{|c|c|c|c|c|c|c|c|c|c|c|c|c|}
\hline Country & State/Region & $\begin{array}{c}\text { River } \\
\text { names }\end{array}$ & $\begin{array}{c}\text { Climate } \\
\text { type }\end{array}$ & $\begin{array}{l}\text { Cacthment } \\
\text { area }\left(\mathrm{km}^{2}\right)\end{array}$ & $\begin{array}{c}\text { Spatial drying } \\
\text { pattern }\end{array}$ & $\begin{array}{c}\text { FI range } \\
(\%)\end{array}$ & $\begin{array}{c}\text { Sampling } \\
\text { method }\end{array}$ & $\begin{array}{c}\text { Duration } \\
(\mathrm{yr})\end{array}$ & $\begin{array}{c}\text { No. } \\
\text { dates }\end{array}$ & $\begin{array}{l}\text { No. } \\
\text { sites }\end{array}$ & Sample size & References \\
\hline France & Provence & Asse & Mediterranean & 657 & Middle & $0-20$ & Hess & 3 & 5 & 13 & 49 & unpub. \\
\hline France & Rhône-Alpes & Albarine & Temperate & 313 & Lower & $0-90$ & Hess & 3 & 5 & 18 & 76 & Datry 2012 \\
\hline Germany & East Westphalia & Alme & Temperate & 763 & Middle & $0-35$ & Kick-net & 3 & 3 & 7 & 21 & unpub \\
\hline Germany & East Westphalia & Ellerbach & Temperate & 91 & Lower & $0-77$ & Surber & 1 & 4 & 3 & 12 & unpub. \\
\hline Germany & East Westphalia & Menne & Temperate & 8 & Lower & $0-40$ & Surber & 1 & 2 & 3 & 6 & Meyer et al. 2003 \\
\hline Germany & East Westphalia & Sauer & Temperate & 109 & Lower & $0-60$ & Kick-net & 5 & 2 to 4 & 14 & 36 & unpub \\
\hline New Zealand & Canterbury & Selwyn & Temperate & 975 & Middle & $0-92$ & Hess & 5 & 2 to 10 & 16 & 73 & Arscott et al. 2010 \\
\hline UK & Kent & Little Stour & Temperate & 213 & Middle & $0-20$ & Kick-net & 9 & 8 & 9 & 72 & Wood and Armitage 2004 \\
\hline US & Massachusetts & Fish & Temperate & 47 & Upper & $0-30$ & Surber & 2 & 3 & 8 & 24 & Santos and Stevenson 2011 \\
\hline US & Arizona & Garden & Arid & 34 & Lower & $0-95$ & Kick-net & 1 & 1 & 9 & 9 & Bogan et al. 2013. \\
\hline US & Arizona & Huachuca & Arid & 25 & Lower & $0-90$ & Kick-net & 1 & 1 & 9 & 9 & Bogan et al. 2013. \\
\hline US & Illinois & Little Lusk & Temperate & 43 & Upper & $0-82$ & Hess & 2 & 2 & 4 & 7 & unpub. \\
\hline US & Indiana & Sycamore Branch & Temperate & 3 & Upper & $0-65$ & Hess & 2 & 2 & 4 & 7 & unpub. \\
\hline
\end{tabular}


Table 2. Number of taxa (No.) and corresponding proportion (\%) across species, genera,

542 families and other taxonomic units for the different levels of taxonomic resolution used

543 in the study (TR1, 2 and 3). The taxonomic resolution for each group of taxa is also

544 detailed. Ph: phylum, c: class, sc: sub-class, f: family, sf: sub-family, g: genus, s: species.

545 EPT: Ephemeroptera, Plecoptera and Trichoptera.

546

\begin{tabular}{ccccccccc} 
& \multicolumn{2}{c}{ TR1 } & & \multicolumn{2}{c}{ TR2 } & & \multicolumn{2}{c}{ TR3 } \\
\cline { 2 - 3 } \cline { 8 - 9 } \cline { 8 - 9 } & No. & $\%$ & & No. & $\%$ & & No. & $\%$ \\
\hline Species & 249 & 43 & & 0 & 0 & & 0 & 0 \\
Genera & 234 & 40 & & 256 & 72 & & 0 & 0 \\
Families & 85 & 15 & & 85 & 24 & & 118 & 94 \\
Others & 17 & 3 & & 17 & 5 & & 7 & 6 \\
Total & 585 & 100 & & 358 & 100 & & 125 & 100
\end{tabular}

Taxonomic

resolution

\begin{tabular}{|c|c|c|c|}
\hline Plecoptera & $f, g, s$ & $f, g$ & $f$ \\
\hline Trichoptera & $f, g, s$ & $f, g$ & $f$ \\
\hline Ephemeroptera & $f, g, s$ & $f, g$ & $f$ \\
\hline Coleoptera & $f, g, s$ & $f, g$ & $f$ \\
\hline Diptera $^{*}$ & $f, s f, g, s$ & $f, s f, g$ & $f$ \\
\hline Odonata & $f, g, s$ & $f, g$ & $f$ \\
\hline Megaloptera & $f, g, s$ & $f, g$ & $f$ \\
\hline Hemiptera & $f, g, s$ & $f, g$ & f \\
\hline Heteroptera & $f, g, s$ & $f, g$ & f \\
\hline Amphipoda & $f, g, s$ & $f, g$ & $f$ \\
\hline Decapoda & $f, g, s$ & $f, g$ & $f$ \\
\hline Isopoda & $f, g, s$ & $f, g$ & $f$ \\
\hline Copepoda & sc & sc & sc \\
\hline Ostracoda & c & c & $\mathrm{c}$ \\
\hline Cladocera & 0 & 0 & 0 \\
\hline Mollusca & $f, g, s$ & $f, g$ & $f$ \\
\hline Oligochaeta & $s c, f, s$ & $s c, f$ & $\mathrm{sc}$ \\
\hline Hirudinae & $s c, f$ & $s c, f$ & sc \\
\hline Plathyhelminth & ph, $f$ & $\mathrm{ph}, \mathrm{f}$ & ph, f \\
\hline Vemathelminthes & $\mathrm{ph}$ & ph & ph \\
\hline Nematomopha & ph, f & $\mathrm{ph}, \mathrm{f}$ & ph, f \\
\hline Acari & sc & sc & sc \\
\hline
\end{tabular}

$547{ }^{*}$ Chironomidae subfamilies (Diamesinae, Orthocladinae, Podonominae, and Tanypodinae)

548 and tribes (Chironomini and Tanytarsini) were used across TR1, TR2, and TR3 
549 Table 3. Community nestedness for different taxonomic levels (TR1, 2 and 3, see table 2). Values shown are the discrepancy indexes and the

550 associated p-values from testing indexes against constrained null models. Italics indicate significant p-values.

551

\begin{tabular}{|c|c|c|c|c|c|c|c|c|c|c|c|c|c|c|}
\hline \multirow[b]{2}{*}{$\begin{array}{r}\text { Taxonomic } \\
\text { level }\end{array}$} & \multicolumn{3}{|c|}{ Upper reach drying } & \multicolumn{5}{|c|}{ Middle reach drying } & \multicolumn{6}{|c|}{ Lower reach drying } \\
\hline & Fish Brook & $\begin{array}{c}\text { Sycamore } \\
\text { Branch }\end{array}$ & Little Lusk & Asse & Orari & Selwyn & Little Stour & Alme & Albarine & Huachuca & Garden & Ellerbach & Menne & Sauer \\
\hline$\overline{\text { TR1 }}$ & $53 ; 0.01$ & $30 ; 0.21$ & $24 ; 0.03$ & $29 ; 0.55$ & $81 ; 0.01$ & $123 ; 0.01$ & $75 ; 0.15$ & $93 ; 0.01$ & $73 ; 0.01$ & $7 ; 0.01$ & $8 ; 0.01$ & $75 ; 0.01$ & $18 ; 0.49$ & $257 ; 0.01$ \\
\hline TR2 & $39 ; 0.07$ & $28 ; 0.13$ & $28 ; 0.05$ & $29 ; 0.51$ & $54 ; 0.01$ & $69 ; 0.09$ & $51 ; 0.45$ & $75 ; 0.01$ & $60 ; 0.01$ & $3 ; 0.01$ & $3 ; 0.01$ & $57 ; 0.01$ & $16 ; 0.59$ & $217 ; 0.01$ \\
\hline TR3 & $49 ; 0.98$ & $17 ; 0.33$ & $22 ; 0.49$ & $24 ; 0.35$ & $38 ; 0.23$ & $45 ; 0.39$ & $42 ; 0.31$ & $57 ; 0.01$ & $87 ; 0.01$ & $1 ; 0.01$ & $1 ; 0.01$ & $33 ; 0.01$ & $10 ; 0.37$ & $147 ; 0.01$ \\
\hline
\end{tabular}




\section{Figure caption}

554 Figure 1. Conceptual diagrams for temporary rivers. A: predicted invertebrate taxon richness 555 patterns along flow intermittence gradients. B: predicted changes in invertebrate community 556 composition along flow intermittence gradients. C: spatial drying patterns in river networks 557 (after Lake, 2003). In B, greyscale boxes represent taxa present at different points along a 558 flow intermittence gradient. Communities structured by resilience are completely nested, 559 because taxa-poor communities at the most temporary reaches are subsets of taxa-rich communities from the least temporary and perennial reaches. Communities structured by resistance are only partially nested and have high rates of taxa replacement by temporary-flow specialists along the flow intermittence gradient. In C, solid and dashed lines represent 563 perennial and temporary reaches, respectively.

Figure 2. Average mixed-effects models for the 14 data sets of TR1 (white circles, dotted lines), TR2 (grey circles, plain gray line) and TR3 (black circles, plain black line) and FI as a

567 fixed slope, showing a congruent decrease in the number of taxa with increasing FI, 568 regardless of the taxonomic resolution. Linear regressions performed on each dataset 569 individually indicated significant relationships between taxon richness and FI in 11, 10 and 9 570 rivers out of 14, when considering TR1, 2 and 3, respectively.

572 Figure 3. Average (black) and river-specific (grey) mixed-effects models for the 14 data sets 573 of the relative abundance of EPT (Ephemeroptera, Plecoptera and Trichoptera) taxa in 574 communities and FI. Linear regressions performed on each dataset individually indicated 575 significant relationships in 6 rivers out of 14. 
577 Figure 4. Average (black) and river-specific (grey) mixed-effects models for the 14 data sets

578 of the relative abundance of Diptera in communities and FI Linear regressions performed on 579 each dataset individually indicated significant relationships in 8 rivers out of 14 .

580

581

582

583

584

585

586

587

588

589

590

591

592

593

594

595

596

597

598

599

600

601 
A)

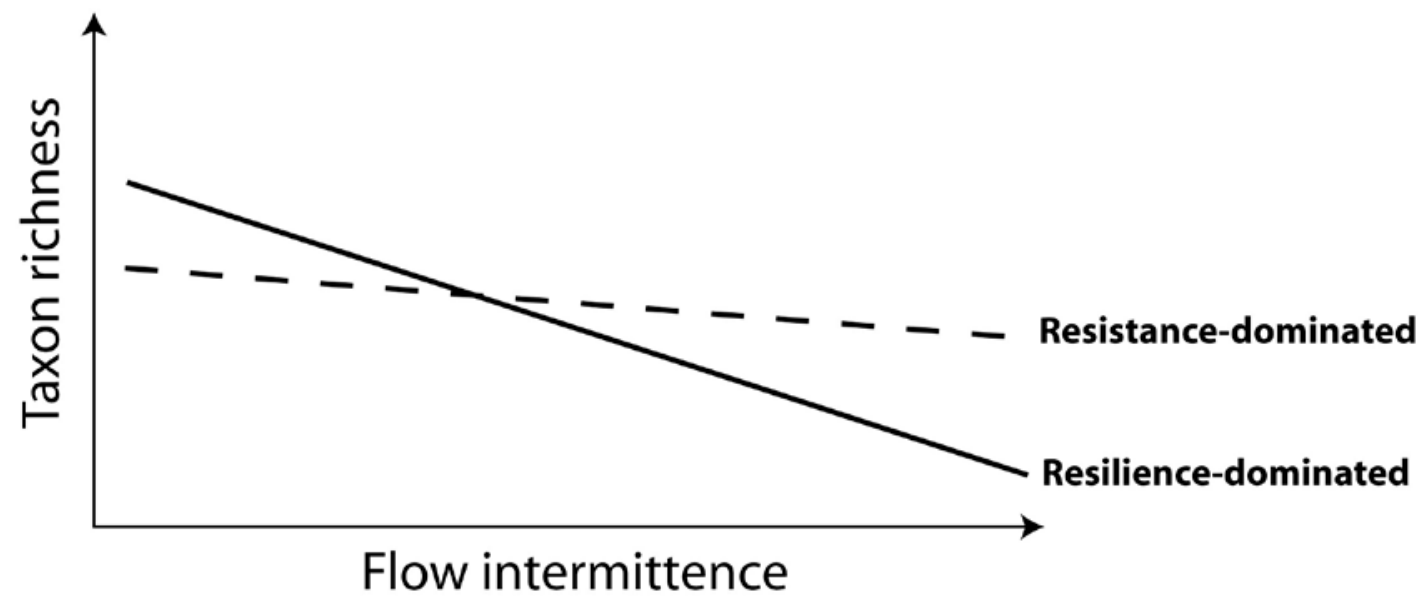

B)
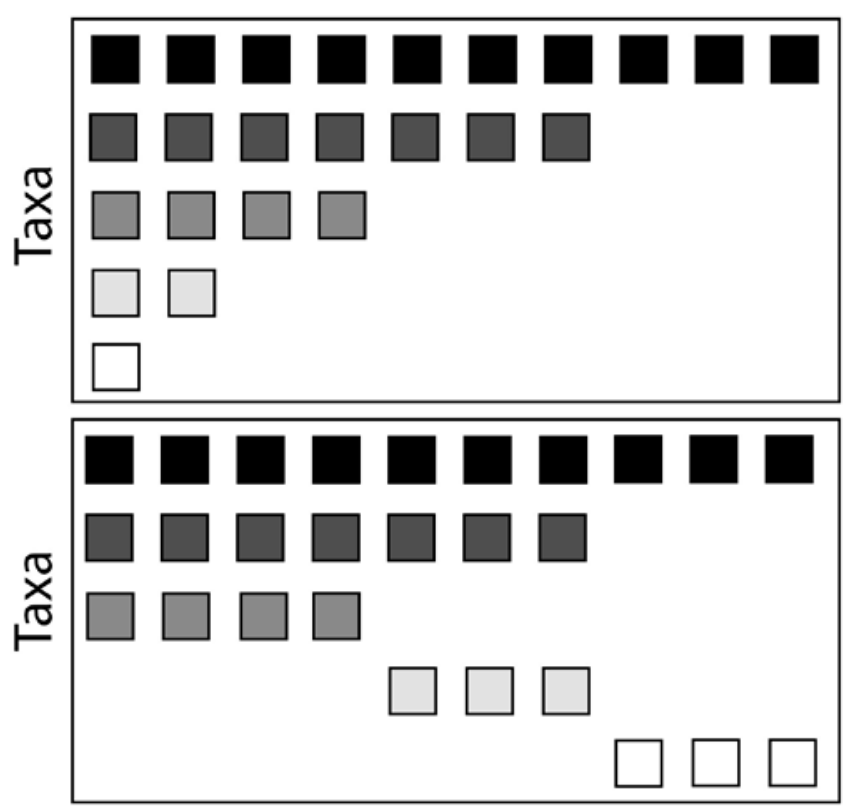

Low Flow intermittence High

C)

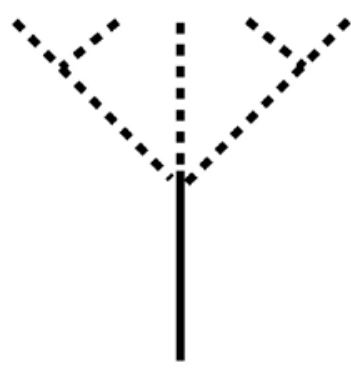

Upper

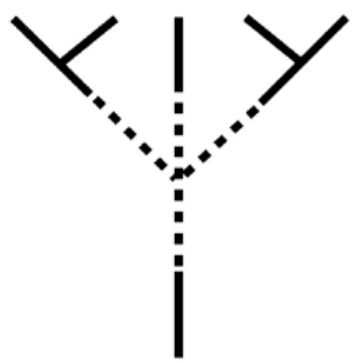

Middle
Resistance-dominated:

Taxa replacement from perennial to temporary-flow specialists along

flow intermittence gradients

Resilience-dominated:

Community nestedness along flow intermittence gradients

Figure 1. 


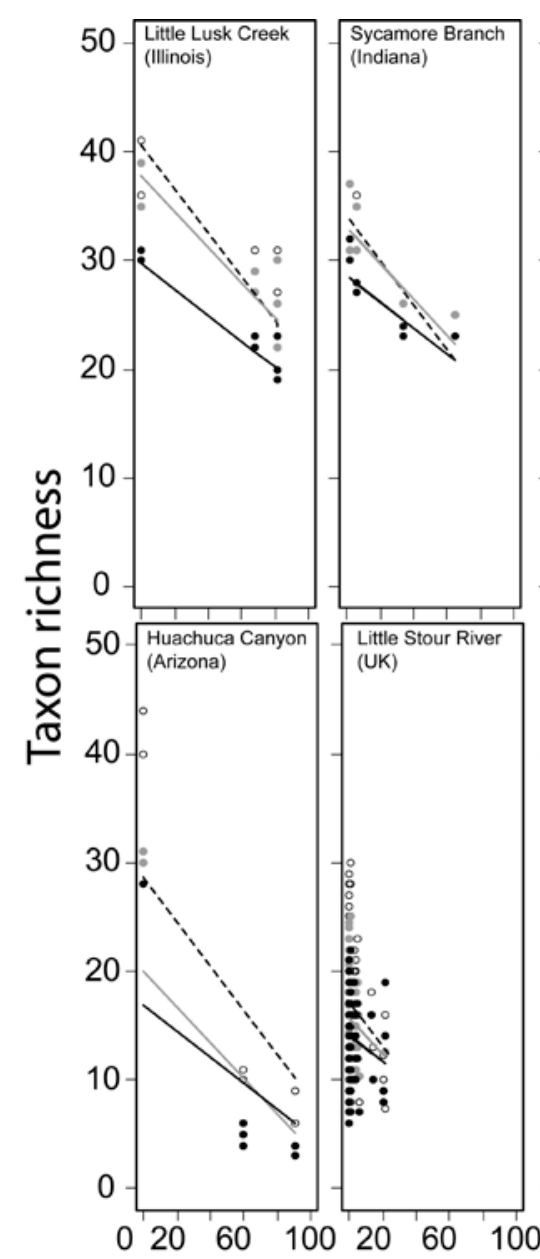

605

606

607 Figure 2.

608

609

610

611

612

613

614

615

616

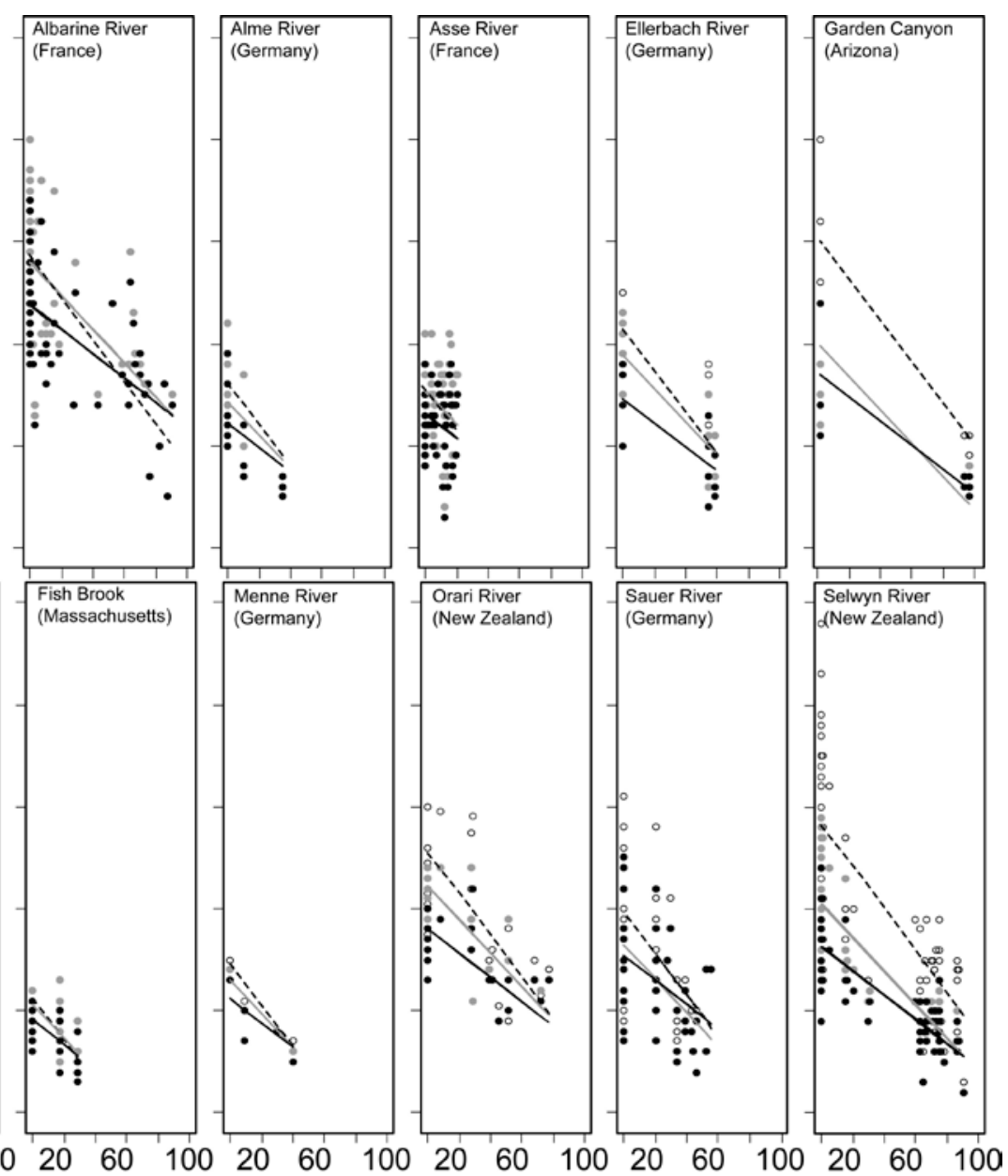

Flow intermittence (\%) 

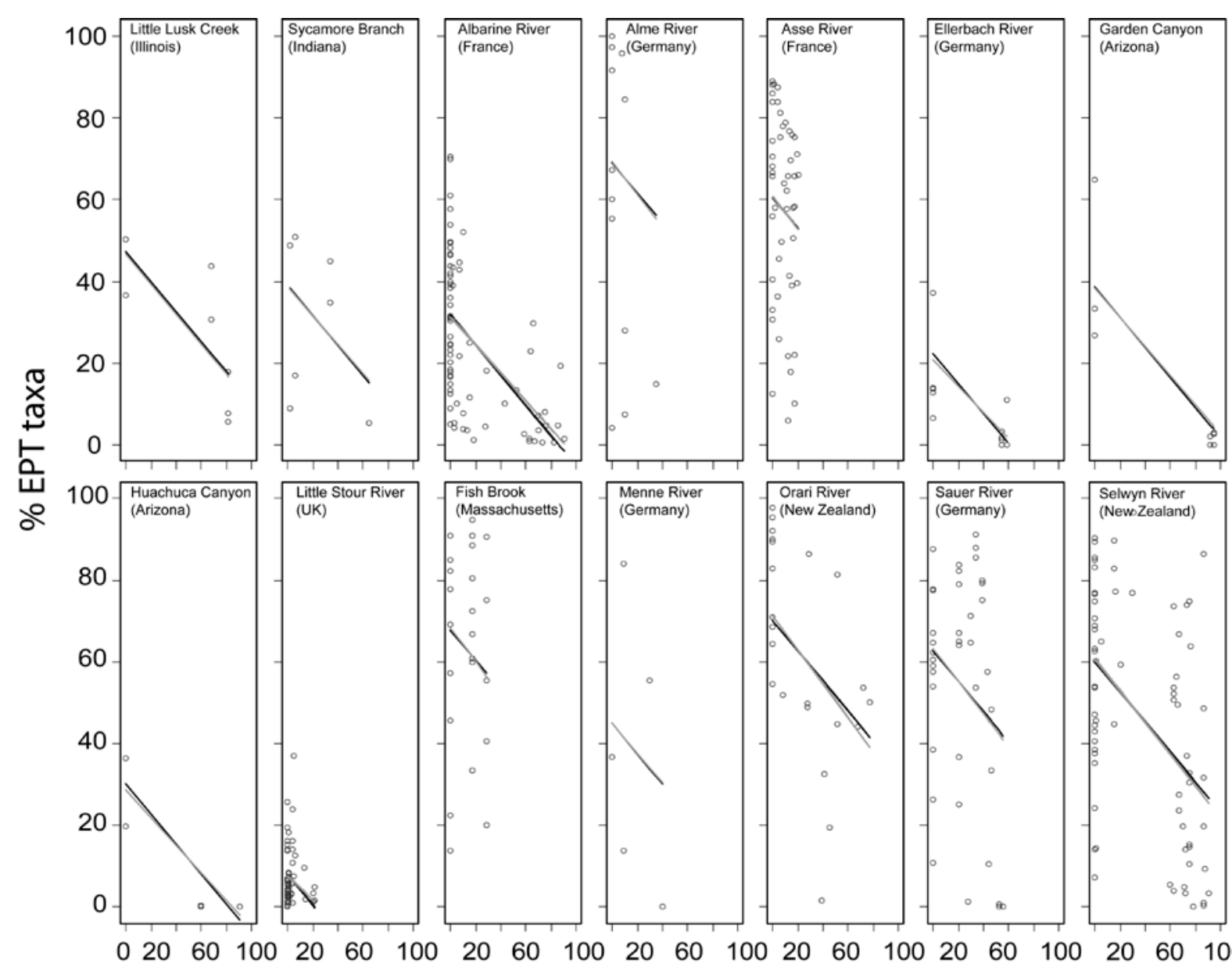

Figure 3.

620

621

622

623

624

625

626

627

628 


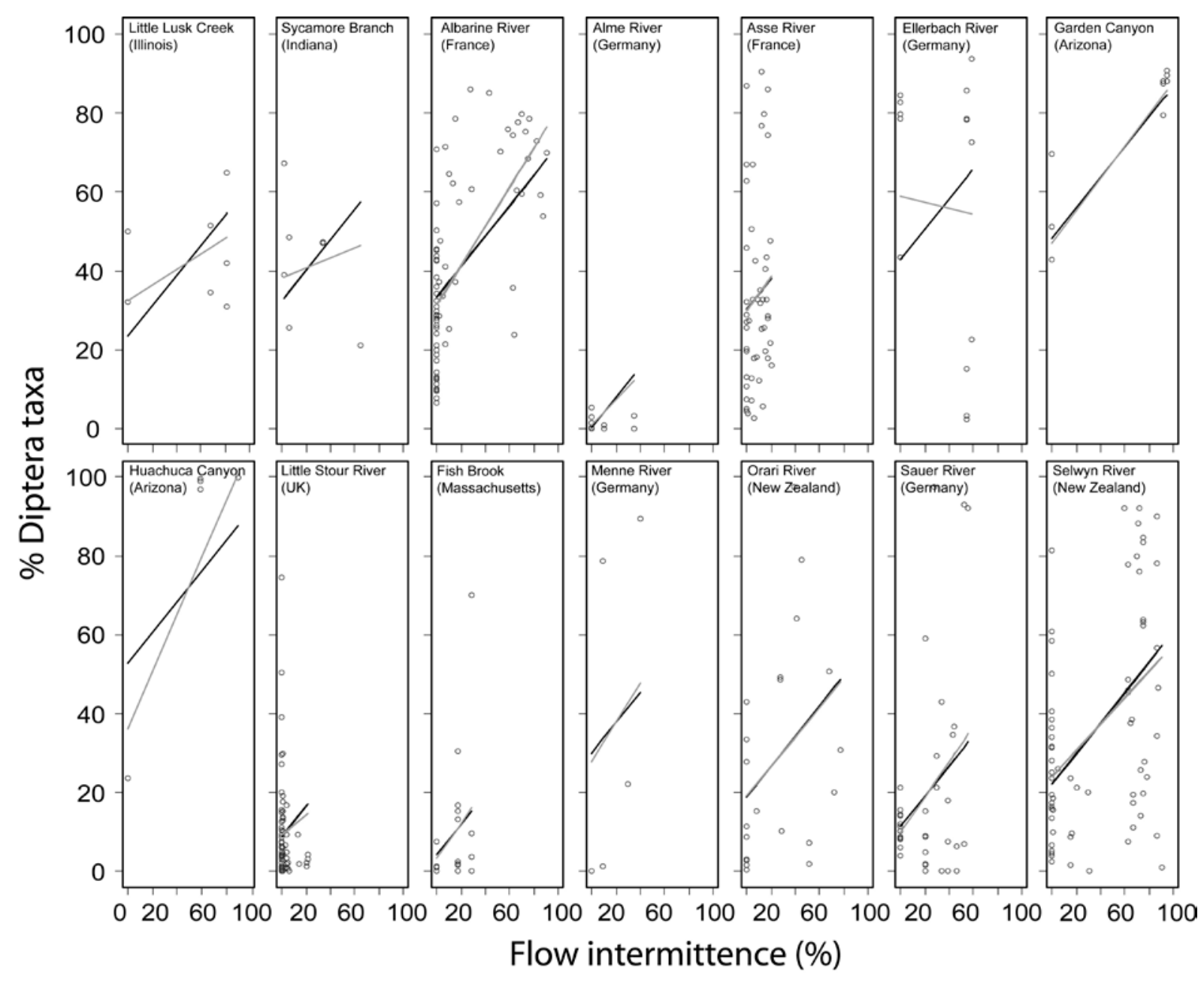

630

631

632 Figure 4.

633

634

635

636

637

638

639 


\section{Appendix S1: characteristics of individual studies.}

\section{Little Stour, United Kingdom}

\section{Physical setting}

The Little Stour River is located in south-east England and drains a 213- $\mathrm{km}^{2}$ catchment in permeable chalk terrain. The river flows $11.5 \mathrm{~km}$ from a perennial spring head to its confluence with the Great Stour River; sampling sites were located in the upper $2.5 \mathrm{~km}$ of the Little Stour. The chalk bedrock is overlain by alluvium in the mid-reaches of the river and there are high seepage losses into the porous alluvium during baseflow periods. The Little Stour flows along its entire length during most years; flow cessation has occurred on three occasions in the last century, in 1949, 1991-1992 and 1996-1997. Severe droughts in those years, in combination with groundwater abstraction for public water supplies, caused a $750 \mathrm{~m}$ reach to dry, $2 \mathrm{~km}$ downstream of the spring head. Flow and invertebrate data from the 19911992 and 1996-1997 droughts are included in this study. During both droughts, the 750 mlong temporary reach was dry for up to 15 months. Flow resumption occurred rapidly at the end of the droughts in the early winters of 1992 and 1997, although recovery of groundwater levels and surface flows to normal conditions took two years (Wood \& Armitage 2004).

\section{Invertebrate sampling}

Invertebrates were collected from nine riffle-run habitats at nine sites (three temporary, six perennial) on the upper $2.5 \mathrm{~km}$ of the river during baseflow periods between 27 August and 3 September in each of nine years (1992-1999). Samples could not be collected from two dry sites in 1992 and 1997. Samples were collected using two-minute kick-samples with a handnet (250- $\mu \mathrm{m}$ mesh net). Samples were preserved in the field with $4 \%$ formaldehyde. Most aquatic insects were identified to species except dipterans, which were identified to family, and baetid mayflies, which were identified to genus. Molluscs were identified to species 
except sphaeriid bivalves, which were identified to family. Oligochaetes and mites were identified to order. For more details on invertebrate sampling and processing, see Wood \& Armitage (2004).

\section{Albarine, France}

Physical setting

The Albarine River is located in temperate eastern France and drains a 313-km² catchment. The river flows for $45 \mathrm{~km}$ through the Jura Mountains, then $15 \mathrm{~km}$ across an alluvial plain to its confluence with the Ain River. On the alluvial plain the river is perched 1-14 m above the regional water table, and the river loses flow to the underlying vadose zone and aquifer at an average rate of $0.4 \mathrm{~m}^{3} \mathrm{~s}^{-1} \mathrm{~km}^{-1}$. The entire alluvial plain reach is temporary due to the rapid seepage loss. Descriptions of the climate, geology and geomorphology of the Albarine River catchment are given in Datry (2012). Flow cessation begins in spring of most years at the confluence with the Ain River, and the drying front moves upstream over the summer. Flow resumption along the entire temporary reach generally occurs in late autumn/early winter. Flow intermittence and average annual dry event duration and frequency all increase with distance downstream. At the downstream end of the temporary reach, annual flow intermittence ranges from 50 to $90 \%$.

\section{Invertebrate sampling}

Invertebrates were collected from riffles at 18 sites (seven perennial, 11 temporary) prior to flow cessation in spring (30 March 2009 and 27 May 2010) and autumn, $\geq 3$ weeks after flow resumption (15 October 2008, 1 December 2010 and 12 October 2010). In October 2008, the five sites furthest downstream were not sampled because they dried two weeks after flow resumption. At each site and each sampling date, two invertebrate samples were collected at 
each of two riffles and composited. Invertebrates were collected with a Hess sampler (0.125$\mathrm{m}^{2}$ area, 200- $\mu \mathrm{m}$ mesh), and preserved with $96 \%$ ethanol. Most aquatic insects and all molluscs were identified to genus or species, and crustaceans, annelids and mites to genus, family or order. For more details on invertebrate sampling and processing, see Datry (2012).

\section{Asse, France}

\section{Physical setting}

The Asse River is located in the Provence region of southeastern France, and drains a 657$\mathrm{km}^{2}$ catchment in the southwestern French Alps. The main tributaries of the Asse River rise in the Préalpes de Digne, then converge $45 \mathrm{~km}$ downstream to form the Asse River mainstem, which flows for $30 \mathrm{~km}$ across an alluvial plain to its confluence with the Durance River. On the alluvial plain, the upper $15 \mathrm{~km}$-long reach is perennial and the lower $15 \mathrm{~km}$-long reach is temporary. Flow intermittence is caused by the combined effects of seepage into the underlying aquifer, high groundwater abstraction in the floodplain for agriculture, and bed aggradation. Along the temporary section, drying events occurred at two 4 km-long reaches spaced $7 \mathrm{~km}$ apart. Descriptions of the climate, geology and geomorphology of the Asse River catchment are given in Mano et al. (2009).

\section{Invertebrate sampling}

Invertebrates were collected from riffles at 13 sites (eight temporary, five perennial). Samples were collected in spring, just before the beginning of summer dry events (15 April March 2009 and 8 June 2010), and in autumn, at least 3 weeks after flow resumption (2 October 2008, 10 November 2010 and 19 October 2010). On each sampling date, two invertebrate samples were collected at each of two riffles per site, and the duplicate samples were composited. Invertebrates were collected using a Hess sampler $\left(0.125-\mathrm{m}^{2}\right.$ area, $200-\mu \mathrm{m}$ 
mesh), and preserved with 96\% ethanol. Most aquatic insects and all molluscs were identified to genus or species, and crustaceans, annelids and mites to family, order or genus.

\section{Sycamore Branch, USA}

Physical setting

Sycamore Branch drains a forested 3.1- $\mathrm{km}^{2}$ catchment in the Charles C. Deam Wilderness Area of the Hoosier National Forest, south-central Indiana, USA. The stream flows for $3.4 \mathrm{~km}$ from its headwaters to the South Fork Arm of the Monroe Lake reservoir. The upper $2 \mathrm{~km}$ of Sycamore Branch have alternating perennial and temporary reaches, and the lower $1.4 \mathrm{~km}$ is perennial. Flow is primarily derived from overland flow, and secondarily from soil water and hillslope groundwater seepage. Drying occurs when soil water is depleted and the groundwater table falls below the streambed elevation. Flow intermittence generally decreases in the downstream direction. The uppermost study reach had the greatest flow intermittence (65\%). Descriptions of the climate, geology, and vegetation of the area given in Homoya et al. (1984) and Thompson (2004).

\section{Invertebrate sampling}

Four 30-m long sampling reaches (two perennial, two temporary) were established along the upper $1.9 \mathrm{~km}$ of Sycamore Branch. Invertebrates were collected from riffles and pools in each reach. Samples were collected during wet (25 June 2003 and 7 April 2004) and dry periods (22 September 2003 and 11 August 2004) when surface water was present in each sampling reach. At each reach, four replicate samples from each habitat type were collected with a modified Hess sampler $\left(0.053-\mathrm{m}^{2}\right.$ area, $250-\mu \mathrm{m}$ mesh) and preserved in $70 \%$ ethanol. Invertebrates were identified to genus or species. For more details on invertebrate sampling and processing, see Fritz et al. (2006). 


\section{Little Lusk, USA}

\section{Physical setting}

Little Lusk Creek drains a 43.2-km² catchment in Shawnee National Forest, southern Illinois, USA. The creek flows $15 \mathrm{~km}$ from its headwaters to its confluence with Lusk Creek. The upper $3 \mathrm{~km}$ are temporary and the lower $12 \mathrm{~km}$ are perennial. Flow is primarily derived from overland flow, and channel drying occurs in the late summer when saturated soil water is depleted and the groundwater table falls below the streambed elevation Flow intermittence generally decreases in the downstream direction. The uppermost study reach had the greatest flow intermittence (82\%). Descriptions of the climate, geology, and vegetation of the area are given in Schwegman (1973) and Thompson (2004).

\section{Invertebrate sampling}

Four 30-m long sampling reaches (one perennial, three temporary) were established along the upper $2.8 \mathrm{~km}$ of Little Lusk Creek. Invertebrates were collected from riffles and pools in each reach. Samples were collected during consecutive dry (30 August 2004) and wet (4 April 2005) seasons when surface was present in each sampling reach. Samples were collected and processed as described above for Sycamore Branch.

\section{Orari, New Zealand}

\section{Physical setting}

The Orari River drains an $850-\mathrm{km}^{2}$ catchment in the eastern foothills of New Zealand's Southern Alps and a portion of the alluvial Canterbury Plains to the east of the foothills. The river flows $45 \mathrm{~km}$ through the foothills to a gorge at the foothills-plains boundary, then $76 \mathrm{~km}$ across the Canterbury Plains to the Pacific Ocean. The section of the river used in the present study extended across the plains from the gorge to a point $3.5 \mathrm{~km}$ upstream from the river 
mouth. The Canterbury Plains are composed of two hydrogeological regions, the inland and coastal plains. The inland plains are underlain by glacial and periglacial gravels. Aquifers in this area are separated from land surface by a deep vadose zone. The coastal plains are underlain by alternating layers of post-glacial gravels and marine clays deposited during high sea stands. Aquifers in this area form a vertical series with the uppermost aquifer at or near ground surface. Flow patterns in the Orari River reflect the contrasting hydrogeological structures. The inland-plains section of the Orari is perched, and the river progressively loses flow to the vadose zone; all flow is lost within $20 \mathrm{~km}$ of the gorge for part of most years. On the coastal plain, upwelling groundwater discharges into the Orari River, starting at a point $49 \mathrm{~km}$ from the gorge and continuing to river mouth. The river gains groundwater with distance downstream in this section, and becomes perennial $\sim 69 \mathrm{~km}$ downstream from the gorge. At the most temporary point of the river, annual average flow permanence is $\sim 60 \%$. When a dry section is present, in expands and contracts in length in response to groundwater level fluctuations and changes in run-off from upstream; the dry section varies from 0 - $50 \mathrm{~km}$ in length. Flow cessation occurs in late spring or early summer of most years. Descriptions of the climate, geology and geomorphology of the Orari River catchment are given in Larned et al. (2011).

\section{Invertebrate sampling}

Invertebrates were collected from riffles at 11 sites (five perennial, six temporary) on 24 October 2007 and 19 February 2008. The river was flowing over its entire length on both sampling dates. At each riffle, four replicate samples were collected with a Surber sampler $\left(0.09-\mathrm{m}^{2}, 250-\mu \mathrm{m}\right.$ mesh), then two samples were combined into each of two composite samples and preserved in 70\% isopropyl alcohol. Most aquatic insects and all molluscs were 
identified to genus or species (some midges were identified to tribe). Crustaceans, annelids, and mites were identified to family or order.

\section{Selwyn, New Zealand}

Physical setting

The Selwyn River drains a 975- $\mathrm{km}^{2}$ catchment located $90 \mathrm{~km}$ north of the Orari River. Like the Orari River, the Selwyn River rises in the foothills of the eastern Southern Alps and flows across the Canterbury Plains. The river mainstem flows $35 \mathrm{~km}$ through the foothills, then 54 km across inland and coastal plains to coastal Lake Ellesmere. The Selwyn River is perched over a deep vadose zone beneath the inland plains, and loses water with distance downstream. The first $3 \mathrm{~km}$ of the losing reach are perennial, and the next $43 \mathrm{~km}$ are temporary. In the coastal plains, upwelling groundwater causes progressive flow gains, and the river becomes perennial approximately $8 \mathrm{~km}$ from its terminus. The severity of intermittence is greater in the Selwyn River than the Orari River, as indicated by higher flow intermittence for most of its length. At the most temporary point of the river, annual average flow intermittence is approximately 70\%. During extended droughts, the river dries for most of its length on the Canterbury Plains, and portions of the central reach may remain dry for more than 1 year. Descriptions of the climate, geology and geomorphology of the Selwyn River catchment are given in Larned et al. (2008).

\section{Invertebrate sampling}

Invertebrates were collected from riffles at 16 sites (three perennial, 13 temporary) on 11 dates between November 2003 and October 2004. At least one site was dry on each sampling date, so the total number of sampling dates at each cross-section varied from 2-11. At each site, four replicate samples were collected with a Surber sampler $\left(0.09-\mathrm{m}^{2}\right.$ area, $250-\mu \mathrm{m}$ 
mesh), then two samples were combined into each of two composite samples and preserved in 70\% isopropyl alcohol. Most insects and all molluscs were identified to genus or species (some midges were identified to tribe). Crustaceans, annelids, and mites were identified to family or order.

\section{Garden and Huachuca, USA}

Physical settings

Huachuca and Garden Canyons are arid-land streams that drain catchments in the Huachuca Mountains in southeast Arizona, USA. Huachuca Canyon drains a 25- $\mathrm{km}^{2}$ catchment before joining the Babocomari River, a tributary of the San Pedro River. Garden Canyon drains a 34$\mathrm{km}^{2}$ catchment before joining the San Pedro River. In the he uppermost $7 \mathrm{~km}$ of both streams, there is interrupted perennial flow through rugged canyons. Downstream of the canyons, the streams flow across alluvial fans where seepage losses are high; both streams become temporary at the canyon-alluvial fan boundaries. The temporary section of Huachuca Canyon extends $12.2 \mathrm{~km}$ to the confluence with the Babocomari River. The temporary section of Garden Canyon extends $22.1 \mathrm{~km}$ to the confluence with the San Pedro River. Flow intermittence in the temporary reaches of both streams increases with distance downstream. Flow intermittence ranges from $40 \%$ at the top of alluvial fans to $99 \%$ several kilometers down the fans. Descriptions of the climate, geology and geomorphology of Garden and Huachuea Canyons are given in Bogan et al. (2013).Descriptions of the climate, geology and geomorphology of Garden and Huachuca Canyons are given in Bogan et al. (2013).

\section{Invertebrate Sampling}

Invertebrates were collected from riffles at nine sites (three perennial, six temporary) from both Huachuca and Garden Canyons on 27-31 March 2010. Sampling sites were spaced 0.25 
to $4 \mathrm{~km}$ apart. Perennial reaches were also sampled in November 2009 and 2010 and March 2011, but the temporary reaches were dry during these periods. During the March 2010 sampling period, the perennial and temporary reaches were connected by flow at both streams. At each sampling site, three replicate samples were collected with a D-net $\left(0.09-\mathrm{m}^{2}\right.$ area, $500-\mu \mathrm{m}$ mesh) by disturbing substrate to a depth of $5 \mathrm{~cm}$ to dislodge invertebrates. The three replicates samples at each site were composited and preserved in 95\% ethanol. All aquatic insects, mites and amphipods were identified to genus or species. All other invertebrates were identified to family or order.

\section{Fish Creek, USA.}

\section{Physical settings}

Fish Brook drains a 47- $\mathrm{km}^{2}$ catchment on the Atlantic Coastal Plain of north-eastern Massachusetts, USA. The Fish Brook mainstem flows $31.25 \mathrm{~km}$ from headwater wetlands to its confluence with the Ipswich River. Descriptions of the climate and geomorphology of the Ipswich River region are given in Zarriello \& Ries (2000). The sampling sites used for this study were located on perennial Fish Brook and two of its temporary headwater tributaries. All sites were within a 1- $\mathrm{km}^{2}$ area of deciduous forested swamp, $5 \mathrm{~km}$ upstream of the Ipswich River confluence.

\section{Invertebrate Sampling}

Invertebrates were collected from riffles and pools at eight sites (three perennial, five temporary) on eight days in July 2004, six days in September 2004, and six days in April 2005. At each sampling site, three replicate samples were collected with a D-net $\left(0.1 \mathrm{~m}^{2}\right.$ area, $500-\mu \mathrm{m}$ mesh) and preserved in 80\% ethanol. All invertebrates were identified to genus. 


\section{Alme and tributaries, Germany.}

\section{Physical setting}

The Alme River drains a 763-km² catchment in East Westphalia, Germany. The river flows north for $60 \mathrm{~km}$ from its headwaters in the northeastern Sauerland region to its confluence with the Lippe River. The Alme River mainstem and three of its tributaries were sampled, the 28-km long Ellerbach River (catchment area $91 \mathrm{~km}^{2}$ ), the 8-km long Menne River (catchment area 8 km²), and the 30- km long Sauer River (catchment area $109 \mathrm{~km}^{2}$ ).

Seepage losses into limestone fissures and sinkholes cause flow intermittence in Alme and its tributaries. The Alme, Ellerbach and Sauer Rivers have perennial reaches extending from the headwaters downstream for 18-31 km, and temporary middle and lower reaches. The Menne River is in a completely karstified catchment and has alternating temporary and perennial reaches for its entire length. The 5-250 m-long perennial reaches in the Menne River are each downstream of a spring. The temporary reaches of the Ellerbach, Menne, and Sauer Rivers extend to their confluences with the Altenau River, which flows into the Alme. The temporary reach of the Alme River ends at the confluence with the Altenau, and the Alme is perennial from this point to its confluence with the Lippe River. Descriptions of the hydrology and geology of the Alme River and its catchment are given in Meyer \& Meyer (2000), and Meyer et al. (2004).

\section{Invertebrate sampling}

In the Alme River, invertebrates were collected at seven sites (four perennial, three temporary) on three dates between 2005 and 2008. At each site, two or three replicate samples were taken with a Surber sampler $\left(0.09-\mathrm{m}^{2}, 250-\mu \mathrm{m}\right.$ mesh). In the Ellerbach River, invertebrates were collected at three sites (one perennial, two temporary) on four dates in 
2001. At each site, three replicate samples were taken with a Surber sampler $\left(0.09-\mathrm{m}^{2}, 250\right.$ $\mu \mathrm{m}$ mesh). In the Menne River, invertebrates were collected at four sites (one perennial, three temporary) on three dates in 2000. At each site, two replicate samples were taken with a Surber sampler $\left(0.09-\mathrm{m}^{2}, 250-\mu \mathrm{m}\right.$ mesh). In the Sauer River, invertebrates were collected at 14 sites (four perennial, 10 temporary) on three dates between 2000 and 2007. At each site, two replicate samples were taken with a Surber sampler $\left(0.09-\mathrm{m}^{2}, 250-\mu \mathrm{m}\right.$ mesh). Invertebrate samples were preserved in $90 \%$ ethanol. All aquatic insects, mites, annelids, molluscs and amphipods were identified to genus or species. All other invertebrates were identified to family or order.

\section{References}

Bogan, M.T., et al. 2013. Flow intermittency alters longitudinal patterns of invertebrate diversity and assemblage composition in an arid-land stream network. -Freshwater Biology. DOI: 10.1111/fwb.12105

Datry, T. 2012. Benthic and hyporheic invertebrate assemblages along a flow intermittence gradient: effects of duration of dry events. - Freshwater Biology 57: 563-574.

Fritz, K.M. et al. 2006. Field Operations Manual for Assessing the Hydrologic Permanence and Ecological Condition of Headwater Streams. EPA 600/R-06/126. USEPA Office of Research and Development, National Exposure Research Laboratory, Cincinnati, $\mathrm{OH}$, USA. http://www.epa.gov/nerleerd/methods/headwater.html

Homoya, M.A. et al. 1984. The natural regions of Indiana. - Proceedings of the Indiana Academy of Sciences 94: 245-268.

Larned, S.T. et al. 2008. The Selwyn River of New Zealand: a benchmark system for alluvial river plain rivers. - River Research \& Application 24: 1-21.

Larned, S.T. et al. 2011. Longitudinal river ecohydrology: flow variation down the lengths of alluvial rivers. -Ecohydrology 4: 532-548.

Mano, V. et al. 2009. Assessment of suspended sediment transport in four alpine watersheds (France): influence of the climatic regime. - Hydrological Processes 23: 777-792.

Meyer, A. and Meyer, E.I. 2000. Discharge regime and the effect of drying on macroinvertebrate communities in a temporary karst stream in East Westphalia (Germany). -Aquatic Sciences 62: 216-231.

Meyer, A., et al. 2004. The effect of low flow and stream drying on the distribution and relative abundance of the alien amphipod, Echinogammarus berilloni (Catta, 1878) in a karstic stream system (Westphalia, Germany). —Crustaceana 77: 909-922.

Santos, A.N. and Stevenson, R.D. 2011. Comparison of Macroinvertebrate Diversity and Community Structure among Perennial and Non-Perennial Headwater Streams. Northeastern Naturalist 18: 7-26.

Schwegman, J. 1973. Natural divisions of Illinois. Illinois Department of Conservation, Natural Preservation Commission. Rockford. 32 p. 
Thompson, F.R., III. 2004. The Hoosier-Shawnee Ecological Assessment. General Technical Report NC-244. St. Paul, MN: US Department of Agriculture, Forest Service, North Central Research Station. 267 p. http://nrs.fs.fed.us/pubs/gtr/gtr_nc244.pdf

Wood, P.J. and Armitage, P.D. 2004. The response of the macroinvertebrate community to low flow variability and supra-seasonal drought within a groundwater dominated system. -Archiv für Hydrobiologie 161: 1-20.

Zarriello, P.J. and Ries, K.G. 2000. A precipitation-runoff model for the analysis of the effects of water withdrawals on streamflow, Ipswich River Basin, Massachusetts. WaterResources Investigation Report 00-4029. US Geological Survey, Northborough, Massachusetts. http://pubs.usgs.gov/wri/wri004029/index.html 
Appendix S2. List of life-history traits coded to assign each taxon to the following class: 0 : neither resistant nor resilient; 1 : resilient; 2 : resistant; and 3 : resilient and resistant. Given the coarse taxonomic resolution used (TR 3), we assigned to each taxon the traits which were dominant across the constituent families, genera or species. When a taxa showed exclusively traits from the resistant class, it was classified as resistant ( $\mathrm{n}=37$ taxa). Conversely, when a taxa showed exclusively traits from the resilient class, it was classified as resilient $(\mathrm{n}=37$ taxa). When a taxa showed traits from both the resistant and resilient class, it was classified as resistant and resilient ( $\mathrm{n}=26$ taxa). Last, when no traits was assigned to a taxa, it was classified as without resistant nor resilient $(\mathrm{n}=25$ taxa). 


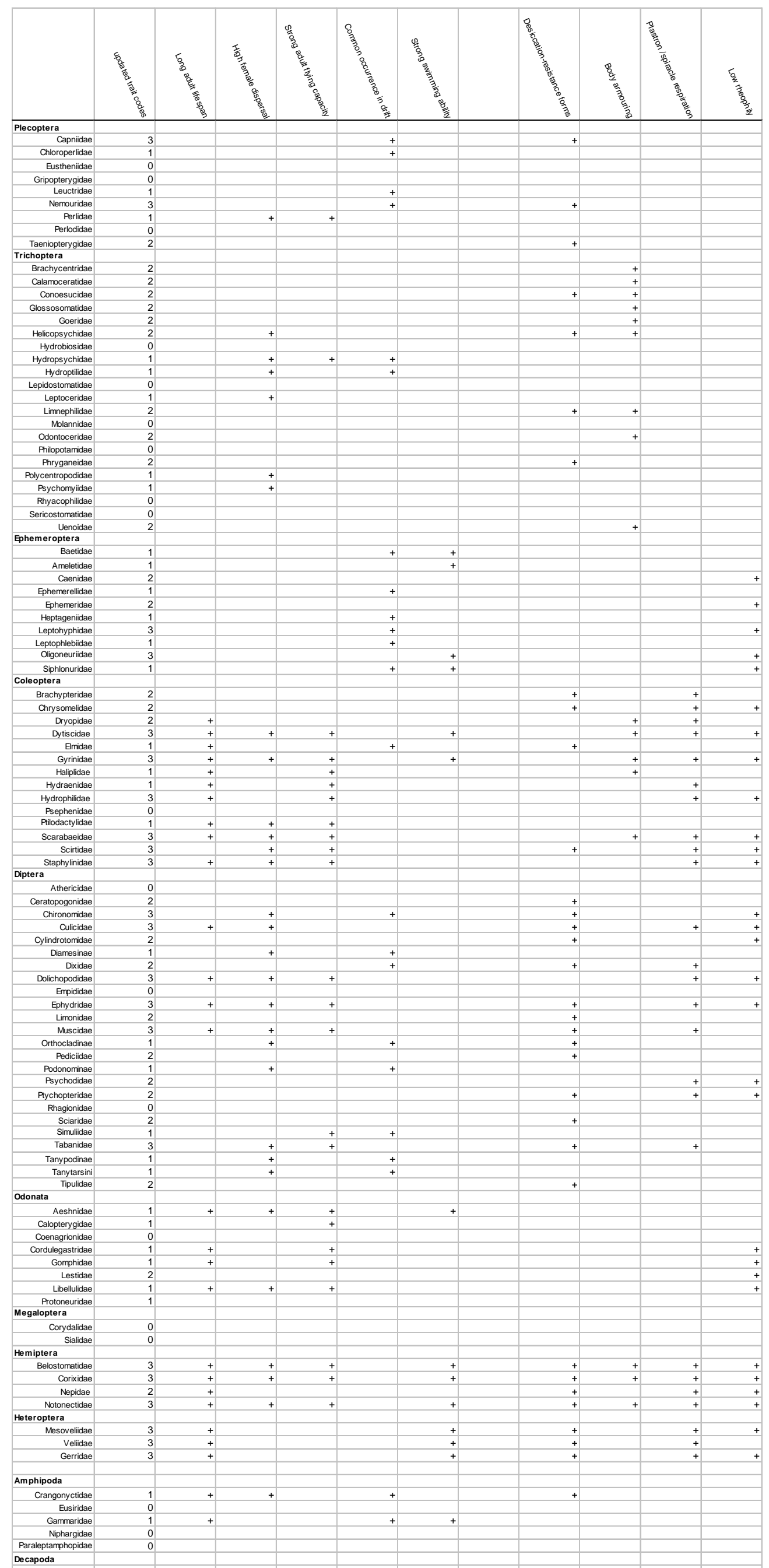

